\title{
Safety, diagnostic, and therapeutic value of flexible bronchoscopy in critically ill COVID-19 patients
}

\author{
Karina Loor, MD (1) • Antonio Álvarez, MD • Almudena Felipe Montiel, MD • \\ Ricard Ferrer, MD, PhD • Oriol Roca, MD, PhD • Marina García-de-Acilu • \\ David Clofent, MD · Jose Cardoso Landivar, MD - Eva Polverino, MD, PhD • \\ Mario Culebras Amigo, MD, PhD
}

Received: 15 September 2020/Revised: 30 November 2020/Accepted: 30 November 2020/Published online: 24 December 2020

(C) Canadian Anesthesiologists' Society 2020

\section{To the Editor,}

A critical factor in the disease caused by severe acute respiratory syndrome coronavirus 2 (SARS-CoV-2) is the difficulty in expectorating/handling secretions. The use of suction catheters to aspirate these secretions is limited because they reach only the main bronchi and not the small airways. Hence, flexible bronchoscopy (FB) has been suggested $^{1,2}$; however, the high risk of transmission due to significant viral aerosolization has supported its relative contraindication. ${ }^{3}$ We report a retrospective study of 222 consecutive FBs performed in 75 patients infected with SARS-CoV-2, confirmed by polymerase chain reaction at the onset of symptoms, and admitted to the intensive care unit with invasive mechanical ventilation. The hospital's ethics committee approved the study and waived the need for informed consent. The primary objective of the study was to determine the main indications for FB, its effect on

Supplementary information The online version of this article (https://doi.org/10.1007/s12630-020-01887-y) contains supplementary material, which is available to authorized users.

K. Loor, MD ( $₫) \cdot$ A. Felipe Montiel, MD · D. Clofent, MD · J. C. Landivar, MD

Department of Respiratory Medicine-Hospital Vall d'Hebron, Universitat Autònoma de Barcelona, Barcelona, Spain

e-mail: kloor@vhebron.net

A. Álvarez, MDM. Culebras Amigo, MD, PhD

Department of Respiratory Medicine-Hospital Vall d'Hebron,

Universitat Autònoma de Barcelona, Barcelona, Spain

CIBER Enfermedades Respiratorias (CIBERES), Barcelona, Spain

R. Ferrer, MD, PhDM. García-de-Acilu Department of Intensive Care, Vall d'Hebron University

Hospital, Barcelona, Spain the clinical management of patients, the safety of the technique, and the associated morbidity and mortality.

Disposable flexible bronchoscopes were used in all cases $\left(A m b u{ }^{\circledR}\right.$ aScope ${ }^{\mathrm{TM}}, 4$ Broncho Regular $5.0 / 2.2$ or Large 5.8/2.8, Ambu A/S. Ballerup, Denmark), and each procedure was performed by an experienced bronchoscopist using personal protective equipment (safety glasses, gown, double gloves, cap, shoe cover, and filtering face piece level 3 [FFP3] mask that can filter at least $99 \%$ of particles $0.3-0.6 \mu \mathrm{m}$ in diameter-i.e., more than FFP2/N95). ${ }^{4}$ Most patients were not in negative pressure rooms. The patient was placed in respiratory apnea with a ventilator pause only when inserting or withdrawing the bronchoscope from the endotracheal tube. Bronchoalveolar lavage was performed in patients with clinical or radiological signs that suggested a significant involvement of the parenchyma/distal airway, and/or suspicion of severe associated respiratory superinfection. ${ }^{3}$

The indications for FB are shown in the Table. The rate of complications was $5.4 \%$. No procedure had to be

O. Roca, MD, PhD

Department of Intensive Care, Vall d'Hebron University

Hospital, Barcelona, Spain

Vall d'Hebron Institut de Recerca (VHIR), Barcelona, Spain

E. Polverino, MD, $\mathrm{PhD}$

Department of Respiratory Medicine-Hospital Vall d'Hebron, Universitat Autònoma de Barcelona, Barcelona, Spain

CIBER Enfermedades Respiratorias (CIBERES), Barcelona, Spain

Vall d'Hebron Institut de Recerca (VHIR), Barcelona, Spain 
suspended. Each patient required a median [interquartile range (IQR)] of 2 [2-4] FB (range 1-18). Most patients were male $(72 \%)$, and the median [IQR] age was 60 [5467] yr (range 24-75 yr). Most patients had no previous pulmonary pathology $(63 / 75 ; 84.0 \%)$, but $86.7 \%$ were obese (median [IQR] body mass index, 30 [26-33] $\mathrm{kg} \cdot \mathrm{m}^{-2}$ ). Overall, 98/222 (44.1\%) FBs were performed in 14 patients who were receiving extracorporeal membrane oxygenation.

Flexible bronchoscopy affected the patient's clinical and/or therapeutic management in more than half of the cases $(122 / 222,55 \%)$ (Table), most commonly extraction of secretions and identification of a pathogen leading to a change in antimicrobials. Secondary infection was found in a large proportion of patients (eAppendix, Electronic Supplementary Material).

The macroscopic endoscopic findings showed normal mucosa $(138 / 222 ; 62 \%)$ or inflammatory/friable mucosa $(84 / 222 ; 38 \%)$. Moreover, there were four types of airway lacerations in four patients, namely, one bronchial and three tracheal, and a metallic stent was placed in each one. All cases occurred after emergent orotracheal intubation with direct laryngoscopy or difficult tracheotomies due to neck anatomy. All patients with lacerations died. The normal macroscopic appearance of the airway does not exclude the existence of lesions that seriously threatened the survival of these patients. The pathophysiologic mechanisms that may be involved (capillary fragility, hypervascularization, iatrogenic, or related to coronavirus disease) are diverse.

Regarding mortality, 23/75 patients $(30.7 \%)$ died after requiring a median [IQR] of 2 [1-5] FBs; in contrast, survivors underwent a median [IQR] of 1 [1-3] FB; $P=$ 0.06 ). The patients who died were older than patients who survived [mean (standard deviation) age, 64 (1) yr vs 56 (2) yr; $P=0.001$ ). There were no deaths resulting from FB.

This was a retrospective study conducted in a single centre. Nevertheless, the data confirm the safety of an increasingly used invasive technique. The current study is one of the largest case series documented in the literature and suggests that performing disposable FB in critically ill patients infected with SARS-CoV-2 is an effective and relatively safe invasive technique that contributes, in many cases, to decision-making. ${ }^{5}$ In addition, none of the bronchoscopists who performed the procedures were infected with SARS-CoV-2. The advantage of disposable bronchoscopes is that they do not require disinfection, further reducing exposure risk for healthcare personnel.

\section{Disclosures None.}

Funding statement None.

Editorial responsibility This submission was handled by Dr. Sangeeta Mehta, Associate Editor, Canadian Journal of Anesthesia.

\section{References}

1. He M, Xiong J, Huang S, Bian Y, Yan P, Redding SR. Airborne precautions recommended in Wuhan, China for bedside fiberoptic bronchoscopy examination of patients with COVID-19. J Infect 2020; 81: e75-7.

2. Vergnon JM, Trosini-Desert V, Fournier C, et al. Bronchoscopy use in the COVID-19 era. Respir Med Res 2020. https://doi.org/10. 1016/j.resmer.2020.100760.

3. Wahidi MM, Lamb C, Murgu S, et al. American Association for Bronchology and Interventional Pulmonology (AABIP) statement on the use of bronchoscopy and respiratory specimen collection in patients with suspected or confirmed COVID-19 Infection. J Bronchology Interv Pulmonol 2020; 27: e52-4.

4. Lentz, RJ, Colt H. Summarizing societal guidelines regarding bronchoscopy during the COVID-19 pandemic. Respirology 2020; 25: 574-7.

5. Chang SH, Jiang J, Kon ZN, et al. Safety and efficacy of bronchoscopy in critically ill patients with coronavirus disease 2019. Chest 2020. https://doi.org/10.1016/j.chest.2020.09.263.

Publisher's Note Springer Nature remains neutral with regard to jurisdictional claims in published maps and institutional affiliations. 